\title{
Testimonios sobre canibalismo en la carta del doctor Chanca al cabildo de Sevilla
}

Sofía Reding Blase*

Recibido el 23 de febrero de 2018; aceptado el 2 de abril de 2018

\section{Abstract}

Doctor Chanca, a physician who accompanied Columbus during the second voyage (1493-1496), wrote a letter to the Council of Seville, the very first description about the caribbean Indians. The document is a portrayal of those men and women, includes not only information provided by savages that Columbus previously qualified as good people, but also a very pessimistic vision about the bad savage to be civilized by Europe. His references to cannibals, that terrified Taino people because of their ferocity, served as a counterweight of the image of the "Noble Savage", and lead us to a reflection about how it promoted the colonization of America and the vigilant eye of ethnographers.

Key words: Chanca, cannibals, witness testimony, colonization.

\section{RESUMEN}

El doctor Chanca, un médico que acompañó a Colón en su segundo viaje (1493-1496), escribió una carta al Cabildo de Sevilla, la cual constituye la primera descripción de los indios del Caribe. El documento es un retrato de los hombres y mujeres; incluye información proveída por los salvajes, a quienes Colón había previamente calificado de buenas personas; también contiene una visión pesimista respecto a poder civilizar al mal salvaje. Sus referencias a los

* Centro de Investigación sobre América Latina y el Caribe, Universidad Nacional Autónoma de México (CIALC, UNAM), correo electrónico: reding@unam.mx 
caníbales, quienes aterrorizaban a los taínos a causa de su ferocidad, sirvieron de contrapeso a la imagen del "Buen salvaje", y nos conducen a una reflexión sobre cómo promovieron la colonización de América y la mirada vigilante de los etnógrafos.

Palabras clave: Chanca, caníbales, declaración testimonial, colonización.

\section{INTRODUCCIÓN}

$\mathrm{D}^{\mathrm{ics}}$ iego Álvarez Chanca (1480-1515) fue un médico que acompañó a Cristóbal Colón durante el segundo viaje trasatlántico, de 1493 a 1496, aunque únicamente permaneció en América por un año. Chanca viajaba por disposición de Isabel y Fernando en calidad de físico (médico y botánico). En una carta dirigida al Cabildo de Sevilla ${ }^{1}$ dejó plasmadas sus observaciones sobre la travesía que siguieron los expedicionarios.

Álvarez Chanca se había embarcado en una de las 17 naves que partieron de Cádiz, lo mismo que el fraile jerónimo Ramón Pané. Ambos fueron, aparentemente, muy cercanos al Almirante, y de algún modo personificaron el doble interés de Colón: averiguar la factibilidad de nuevas rutas mercantiles y, paralelamente, propagar la Buena Nueva. Esto último sería motivo para que Fray Ramón Pané escribiera una Relación acerca de las antigüedades de los indios, la primera etnografía de América, que el propio Almirante le habría solicitado. ${ }^{2}$ La terminó en 1498 , y fue publicada en $1500 .^{3}$

El objetivo de Pané, y para conseguirlo se estableció entre los taínos, era acabar con los propios mitos que recogió: "Por tanto, se debe añadir un título más a este temprano misionero: el primer extirpador de idolatrías". ${ }^{4} \mathrm{Su}$ testimonio, por tanto, no estaba exento de compromisos y, en especial, si se

$1 \quad$ La carta puede hallarse en Gil y Varela (eds.), Cartas de particulares a Colón y Relaciones coetáneas, pp. 155-176. La introducción a este documento es de Varela, quien anota que una copia de la carta está inserta en un códice de 33 hojas, perteneciente al monasterio de la Mejorada, y que se guarda en la Biblioteca de la Real Academia de la Historia de Madrid. La relación se ubica en las páginas 17 a 31 de dicho códice. Ibidem, p. 155.

2 La Relación acerca de las antigüedades de los indios fue utilizada por, al menos, tres personas como soporte de sus estudios: Hernando Colón para su Historia del Almirante don Cristóbal Colón; Pedro Mártir de Anglería para sus Décadas del Nuevo Mundo; y fray Bartolomé de Las Casas para su Apologética historia de las Indias, en la que se afirma que fue el Almirante quien solicitó la investigación. El manuscrito original, entregado al propio Colón, se perdió.

3 Véase el estudio preliminar de Arrom a la Relación en la que se señala, desde la primera página, que dicho documento "constituye la piedra angular de los estudios etnológicos en este hemisferio" (Fray Ramón Pané: Relación acerca de las antigüedades de los indios, p. 1).

$4 \quad$ Cattan, "Fray Ramón Pané. El primer extirpador de idolatrías", p. 37. 
recuerda el propósito de la bula Intercaetera expedida por Alejandro VI, a saber, el reparto del mundo entre España y Portugal y la conversión de los indios. ${ }^{5}$

En su relato - Pané y Chanca debieron hablar al respecto en algún momento- el médico se muestra sumamente desconfiado respecto de la capacidad de los indios para ser cristianizados. El suyo, a diferencia del de Colón, es un relato que desmitifica al buen salvaje descrito por el Almirante, es decir, los indios hospitalarios que conoció durante el primer viaje; Chanca se centra en lo que le contaron sobre los malos salvajes de las Antillas menores, y encuentra en su canibalismo motivo suficiente para desconfiar de ellos. Así pues, la lectura de su carta no sólo aporta una visión más o menos clara del tipo de datos que se consideraban valiosos; también da cuenta del imaginario aún medieval, pero vigente, incluso en aquellos días de aires renacentistas.

\section{Los CANíbales SON GENTE del Gran KaN}

Se ha vuelto costumbre que, al acercarse el décimo mes de nuestro calendario, se enfrenten hispanofilias e hispanofobias, como si fuera un ritual. Y en cierto modo lo es: un ritual de la memoria que permite traer al presente los efectos que, a lo largo de muchos siglos, resultaron de los viajes del Almirante de la Mar Océana: guerra, muerte y destrucción. Como todo rito lo hace, aquel es la escenificación de un mito - el del Salvaje—. El análisis de ese mito, en el que el Salvaje es el significante, es necesario establecer quiénes tildaron a los indios en buenos o malos, según la amabilidad que mostraban o su falta de hospitalidad.

También es importante examinar los motivos que llevaron a robustecer las imágenes de amistad y enemistad y lo que eso significó: crónicas, bitácoras, cartas y diversos documentos, los cuales refirieron la existencia de indios buenos, pero también de indios malos, y ello derivó en el diseño de una política estatal que protegía la vida de los buenos salvajes, mientras que ordenaba esclavizar a los caníbales. En este sentido, remitir a la mirada de Chanca, y no sólo a su punto de vista, lleva a reflexionar sobre los límites de lo humano y el modo en que se decidiría el destino que tendrán los cuerpos de los hombres hallados.

La anterior reflexión alcanzaría mayor grado de intensidad y rigor durante el debate sostenido entre Bartolomé de Las Casas y Juan Ginés de Sepúlveda, en $1550 .^{6}$

5 Esta orden fue dada en 1493, refiriéndose el Papa a la necesidad de evangelizar a la "inmensa cantidad de gente que según se afirma van desnudos y no comen carne", y confirmada en una segunda bula Intercaetera, cuando Colón ya se encontraba en el Caribe.

6 Remito al estudio, tan conciso como ilustrador, de Mauricio Beuchot, La querella de la conquista. Una polémica del siglo XVI (1992), en donde analiza las diversas posturas asumidas en torno a la legitimidad de la presencia española en Indias. 
Fueron los cuerpos de los indios los que, precisamente, llamaron la atención. La primera referencia se halla en el Diario de Colón, escrita tras el primer desembarco en una isla caribeña: "Luego llegaron gente desnuda", y esa frase reactiva un discurso ya conocido, en el que el desabrigo es seña de miseria cultural. Aunque la superioridad armamentística habría bastado para ganar terreno, a Colón no le interesaban las guerras, sino los negocios. Y esos asuntos, los trataría con el Gran Kan, ante el cual presentaría las cartas credenciales que los Reyes habían expedido a su favor. ${ }^{7}$ El Almirante ya comenzaba, desde 1492, a fabular, a "inventar" un escenario asiático y colocarse, colgándose de esa invención, a la altura de Marco Polo. ${ }^{8}$

A pesar de que sus anfitriones le señalan que otras islas están pobladas por caníbales, Colón entendió que le hablaban de los soldados del poderoso monarca mongol: "Caniba no es otra cosa sino la gente del Gran Can, que debe ser aquí muy vecino, y ternán navíos y vernán a captivarlos, y como no vuelven creen que se los han comido" (11 de diciembre de 1492). Días después, se lee en el Diario, Colón seguía negando la presencia de caníbales: "Mostráronles dos hombres que les faltaba algunos pedazos de carne de su cuerpo e hiciéronles creer que los caníbales los habían comido a bocados; el Almirante no lo creyó" (17 de diciembre de 1492).

No será la primera vez que se diga, y con justa razón, que resulta ingenuo creer en el testimonio de un individuo de quien no se sabe casi nada, de quien no hay un solo retrato hecho en vida, y cuya firma es tan excéntrica como enigmática. Más descabellado por cuanto el Diario salido de la pluma de Colón, se encuentra extraviado. No obstante, lo relevante es qué dice y cuáles serían los motivos que lo llevaron a escribir sobre tal o cual evento. Incluso pese a que fue intervenida, su bitácora de viaje es de enorme valía. Lo anterior nos llevará a poner atención en lo que se dijo, y no tanto en la veracidad de lo que se afirmó.

Es fácil comprender cuáles fueron los motivos para negar la presencia de caníbales: a Colón le convenía desechar, de buenas a primeras, toda suspicacia respecto de lo que se había encontrado y, seguramente, para no espantar a quienes patrocinaron su empresa. ${ }^{9}$ Era mucho más adecuado promover la figura del buen salvaje. En cierto sentido, su ficción — engalanada por la pluma

7 Expedidas el 30 de abril de 1492, cuando se le ratificó el título de Almirante de la Mar Océana a Colón.

8 Imposible no mencionar la conocida obra de Edmundo O'Gorman, La invención de América. El universalismo de la cultura de Occidente (1958), así como un trabajo previo, La idea del descubrimiento de América. Historia de esa interpretación y crítica de sus fundamentos (1951).

9 Se sabe que el financiamiento del proyecto de Colón provino de círculos privados. Fray Bartolomé de Las Casas afirma que toda la expedición costó tan sólo dos millones de maravedís. Véase Svet, Cristóbal Colón, p. 135; y Varela, Colón y los florentinos, p. 50. 
de Las Casas - era sólo eso, una falsificación o simulación de la realidad para impactar a sus lectores y asegurar la continuidad de "su" empresa:

Abrumado por lo que sus ojos contemplan, Colón prefiere verlo o reenfocarlo con los ojos de su imaginación y su cultura; cuando una realidad no puede ser comprendida racionalmente, la adapta y la deforma hasta que se parezca a algo familiar, y este proceso lo pone más cerca de la literatura que de la historia: la realidad es un estímulo que despierta (o hipnotiza) los sentidos, el recuerdo y la fantasía. $^{10}$

Colón optó, pues, por torcer la realidad con la misma fuerza con la que la artritis le arqueaba las coyunturas. Desde su primer viaje, capitaneando a navegantes de pésimo comportamiento, el Almirante había optado por la simulación por mucho que la realidad le estallara ante la mirada. ¿No vale la pena, para des-Colón-izarnos, una interpretación de ese primer capítulo del compendio de atrocidades cometidas durante siglos? Auri sacra fames que llevó a una abominable, impúdica, indecente, construcción de una realidad, cuya existencia era sólo virtual y nutrida de una imaginería antiquísima.

Diego Álvarez Chanca, por su parte, parecía perseguir otros derroteros, sin temor a caer víctima de visiones o verse preso en agendas poco adecuadas a sus intereses, a saber, las religiosas. Por ello, sus testimonios relativos a la antropofagia, que evidencian la diferencia de su mirada y la del Almirante, son importantes. Su carta, brevísima en comparación de la ya de por sí corta relación escrita por fray Ramón Pané, debe ser ubicada en la historia de la etnografía, en especial de los cuerpos, tanto de los amables salvajes, como las de los caníbales. Unos y otros, al parecer, practicantes de toda suerte de deformaciones: poligamia, sodomía, tatuajes, desnudez. Debido a sus observaciones, tanto de salvajes que no comen carne humana como de los que sí lo hacen, su testimonio sirve de contrapunto al de Colón. ${ }^{11}$

No obstante, habrá que señalar que, a la postre, se impuso la imagen del buen salvaje, pues servía - y sigue haciéndolo- como un pre-texto, es decir, como argumento demoledor en su señalamiento de fallas sistémicas del programa conquistador. ${ }^{12}$ Ese sería el caso del "sabio desnudo" inventado por Pedro Mártir de Anglería (1457-1526), que reprochaba al colono la barbarie de

Oviedo, Historia de la literatura hispanoamericana. I. De los origenes a la Emancipación, p. 84.

11 De entre los cronistas de Indias, sólo Pedro Mártir de Anglería, afirma Consuelo Varela, parece haber dado muestras de conocer a Chanca, y refiriéndose a él como codicioso, y que por tal motivo había viajado con Colón. Varela refiere que, si bien algunos suponen que Chanca regresó a las Indias en la expedición de Pedrarias Ávila, en 1514, ella no ha hallado evidencia documental que lo pruebe. Juan Gil y Consuelo Varela, op. cit., p. 154.

12 Remito a mi libro El buen salvaje y el caníbal (2009), en que trato la cuestión de la utilidad de la figura del noble salvaje. 
la que hacía gala. ${ }^{13}$ Imposible no mencionar a Bartolomé de Las Casas (14841566), a quien acusan sus detractores de haber colocado la primera piedra a la llamada "leyenda negra", aunque él fue mucho más allá de eso: afirmó que España no tenía más remedio que abandonar América, pues según él —y casi toda la Orden-, la soberanía sobre estas tierras debían ejercerla los nativos. ${ }^{14}$ Montaigne (1533-1592), por su parte, usó las alegorías naturalistas y del buen salvaje para imprimirle fuerza a la queja de Francisco I, quien protestaba por el reparto de tierras hecho a favor de España y Portugal, y para afianzarse en su crítica anti-española. ${ }^{15}$

Esas discusiones, habrá que recordarlo, se dieron cuando ya habían pasado muchos años desde los primeros contactos, y la bibliografía que puede hallarse sobre los protagonistas del debate en torno la legitimidad de la presencia española en América y sus argumentos a favor o en contra, es abundante. En cambio, los estudios relativos a la imagen del mal salvaje son más escasos.

La figura del Caníbal, en contraste con la del salvaje bueno, sirvió para dar sobradas razones para la conquista, justificándola en razón de prácticas que ofendían a los europeos. Además, la presencia de caníbales llevaba a alinearse con los fines colonizadores: se trataba de emprender negocios en Indias, y no tanto de aumentar el número de cristianos. De hecho, ni siquiera en las Capitulaciones, firmadas por Colón y los Reyes en 1492, hay mención al carácter misional o evangelizador del viaje.

No obstante, haber detectado la trasgresión del tabú de la antropofagia modificaba el proyecto, más allá de las refutaciones de Colón en cuanto al canibalismo: ya no se trataba únicamente de engrosar los compendios de rarezas y curiosidades, sino de exterminarlas o, al menos, despojarlas de su bestialidad. En el caso de Colón parecía claro que la empresa, encaminada a llenar de oro las arcas reales - y las suyas-, se sometería a la prédica religiosa. Después de todo, era el Altísimo quien lo había lanzado a cumplir una misión salvífica; se confirma lo anterior cuando Colón escribe (entre 1502 y 1504) en el "Prólogo" a su Libro de las Profecías: "Ya dise que para la hesecuçión de la inpresa de las Indias no me aprovechó rasón ni matemática ni mapamundos; llanamente se cumplió lo que diso Isaías [...]. Acuérdense Vuestras Altezas de

13 Pedro Mártir de Anglería, Década I, lib. III, cap. IV. Resulta de importancia un dato: Anglería había sido contratado, desde 1492, para encargarse de la educación de los caballeros de la Corte, hecho que le colocaba en un lugar privilegiado para visibilizar su idea respecto al salvaje noble y los tonos oscuros de la colonización. Véase: Alberto M. Salas, Tres cronistas de Indias, p. 22.

14 "Se concluye con juristas y canonistas que ni los reyes ni los emperadores tienen poder fundado sobre las haciendas de los ciudadanos, ni sobre la posesión de sus territorios, provincias o tierras del reino ni tampoco sobre el dominio útil ni directo de los habitantes". Bartolomé de Las Casas, De regia potestate o derecho de autodeterminación, p. 23.

15 Montaigne, Ensayos, lib. III, cap. 6. 
los Hevangelios y de tantas promesas que Nuestro Redentor nos fiso y cuán esprimentado está todo". ${ }^{16}$

\section{LOS CARIBES COMEN CARNE HUMANA}

Pasados algunos días tras el arribo al Mar Caribe, cuenta el doctor Chanca, ya se tenían pistas relativas al canibalismo; unos hombres habían traído a bordo algunos huesos de brazos y piernas. Las osamentas hicieron sospechar que las islas "son habitadas de gente que come carne humana", y de las cuales le habían hablado al Almirante durante su primer viaje. Las dudas se disiparon con abrumadoras evidencias que indicaban que los festines antropofágicos eran habituales porque durante los ocho días que duró el ir y venir por las costas, hallaron "infinitos huesos de hombres". Incluso, según narra Chanca, las lugareñas de Marigalante y Dominica - las islas de los caníbales - le dijeron que sus hombres habían partido en diez canoas para traer más víctimas.

Chanca distingue a los caníbales por ser de cabello muy largo — no como los indios aliados, quienes lo traen corto- y por el hecho de que llevan los ojos delineados de negro al igual que las cejas, por lo que "perescían más espantables". Los otros indios —aliados de los españoles-llevan los rostros coloreados. En el caso de las mujeres caníbales, Chanca refiere que llevan cintas atadas debajo de la rodilla y por encima del tobillo, tan ceñidas que deforman sus pantorrillas. Así, en general se trata de cuerpos que se alejan de la norma (europea).

Es importante señalar lo anterior porque, al parecer, Chanca era un espía, aunque no se tiene claro a quién reportaba, pero lo cierto es que su testimonio, además de etnográfico, servía para contrastar con lo que Colón afirmaba. La sospecha de que Chanca servía a intereses más políticos que de otro tipo, tiene que ver con la frase con la que inicia su carta: "Muy Magnífico Señor”. Ello ha hecho suponer a la investigadora Adelaida Sagarra que no iba dirigida a cierto grupo de personas, sino a Juan Rodríguez de Fonseca, Deán del Cabildo de la Catedral de Sevilla y organizador de la segunda expedición de Colón.

En ese contexto podría tener cabida lo que Chanca refiere en cuanto a las moradas de los malos salvajes, que le parecen "de mejor hechura" que las de otros indios, aunque sin querer decir con ello, que se trata de gente comparable a la europea: "que es gente tan bestial que no tiene discreción para buscar logar donde habitar, que los que viven á la marina es maravilla cuán bestialmente edifican, que las casas enderedor tienen tan cubiertas de yerba ó de humedad, que estoy espantado como viven".

16 Colón, Libro de las Profecías, p. 15. Éste es el único libro que se sabe es escrito de su puño y letra. Se conserva en la Biblioteca Colombina de Sevilla. 
También alega que, además del pobre ingenio que los caracteriza, los indios "Comen cuantas culebras é lagartos é arañas é cuantos gusanos se hallan por el suelo, ansí que me parece es mayor su bestialidad que la de ninguna bestia del mundo". La incivilidad no sólo está presente en casa, sino que parece habitar en su corazón: tal vez los salvajes tengan domus, pero no por ello tienen un ethos. Por eso Chanca no confía en los indios, ni siquiera en los aliados de Colón. El fundamento de su habitar es, para él, bestial y no humano.

Llama la atención que, a pesar de su desconfianza, Chanca recolecte información, que escuche lo que le cuentan y tome nota de ello. Así, su testimonio, tanto como el de otros conquistadores, es un "testimonio de testimonios", es decir, que repite lo que los indios van diciendo. ${ }^{17}$ Es cierto que el discurso indígena es un testimonio "cautivo y secuestrado" en medio de un proceso de negociación o de franco enfrentamiento, ${ }^{18}$ pero incluso si los argumentos indios hubiesen sido falsificados, obtendríamos pistas respecto a los móviles de la propia falsificación. Al respecto de la relación del jerónimo Pané, también se ha afirmado que el hecho de que utilice los verbos "dicen" y "creen", funciona como una protección a sus propias creencias y desautoriza las taínas: "Prescindiendo de tal encabezado, la relación adquiriría otra lectura: la narración nativa obtendría la calidad de afirmación". ${ }^{19}$

A Chanca, sin embargo, sí le interesa creer en la existencia de caníbales. Sobre las prácticas antropofágicas, Chanca se entera que las mujeres se comen a los pequeños de sus prisioneras, pero nunca a los propios. También le aseguran que los caníbales no consumen carne de mujeres y mucho menos de muchachos; a éstos los castran y esclavizan para comérselos cuando alcanzan la madurez. Chanca también refiere que varias mujeres fueron hechas cautivas por uno y otro bando —el caníbal y el español—y que eso motivó diversas pugnas debido a que "asomaban queja que los cristianos uno tenia tres mujeres, otro cuatro, donde creemos quel mal que les vino fué de zelos". Un enfrentamiento fue particularmente importante, pues resultó en la muerte de los primeros colonos y, probablemente, por haber sido devorados.

El episodio tuvo que ver con el hallazgo, en ruinas, de lo que fuera el Fuerte de Navidad, edificado con los restos de la Santa María. ${ }^{20}$ No había rastro de ninguno de los 39 hombres que Colón había dejado tras de sí. Al parecer de Chanca: "Ya los teníamos por perdidos é comidos de aquellas gentes que se dicen los Caribes, porque no bastaba razón para creer que eran perdidos de otra

17 Respecto a esta complicación nos pone sobre aviso Martin Lienhardt en su prólogo a la obra Testimonios, cartas y manifiestos indigenas, pp. XVI-XVII.

$18 \quad$ Ibidem, p. XXIII.

19 Cattan, op. cit., p. 46.

20 Según refiere Las Casas, la nao había zozobrado en la noche del 24 al 25 de diciembre de 1492, cuando alguien dejó el gobernalle en manos de un grumete y la nao encalló chocando con una cadena de arrecifes. Véase: Fray Bartolomé de Las Casas, Historia de las Indias, vol. I, cap. 59 . 
manera, porque iban entre ellos pilotos, marineros que por la estrella saben ir é venir hasta España, creíamos que en tan pequeño espacio no se podían perder". ${ }^{21}$

Se barajaron dos hipótesis: o bien los caciques habrían acabado con los colonos debido a que éstos tomaban por fuerza a sus mujeres — “el mal que les vino fue de celos"-, o bien habían muerto buscando oro. Aquellas eran, al menos, las respuestas que daba Guacanagarí, que Colón conocía desde su primer viaje, al tiempo que aseguraba que el ataque al Fuerte había sido obra de los caciques Caonabó y Mayrení. Para darle mayor credibilidad a su dicho, Guacanagarí mostró la pierna que le habían herido durante el combate contra los saqueadores.

A pedido del Almirante, Chanca procedió a revisar al cacique - que se mecía en su hamaca - percatándose de que éste mentía. Pero Colón no cedió ante el fracaso y siguió adelante. Después de todo, no era conveniente desconfiar de sus aliados: donde Chanca creía ver comegentes, Colón veía cuerpos a los que podía poner a trabajar y ojos que buscarían oro para llenar las arcas. En cambio Chanca, a su regreso a casa, reflexionó hondamente sobre los ojos malsanos y sus efectos en quienes son víctimas de su poder, y publicó un libro al respecto en $1499 .{ }^{22}$

\section{OTROS DIMES Y DIRETES}

Un par de individuos también estuvieron involucrados en la descripción del caníbal y ello se debió a que se entrevistaron con los capitanes Pedro Margarit y Antonio de Torres, encargados del viaje de retorno a España en que viajó Chanca.

Guillermo Coma se entrevistó con Pedro Margarit, mientras que Simón Verde se entrevistó con Antonio de Torres. No se sabe con certeza si Coma viajó al Caribe, pero se conoce que escribió a un siciliano amigo suyo, Nicolás Esquilache, comentándole sobre la información que recabó, aparentemente, de quienes volvían de las islas, incluyendo a Chanca. Esquilache tradujo esa carta al latín y en ella predomina un lenguaje figurativo y con analogías claramente renacentistas, propias del ambiente de la época.

En la carta, recogida por Gil y Varela bajo el título de "De las islas del Mar Meridional e Índico recientemente descubiertas", ${ }^{23}$ se refieren varios episodios tocantes a los indios malos, todos ellos mediados por indios aliados

$21 \quad$ Gil y Varela, op. cit., p. 167.

22 Tractatus de Fascinatione (P. Brun, 1502). Un ejemplar se encuentra en Sevilla, en la Biblioteca Colombina y fue adquirida por Hernando Colón en 25 maravedíes. Gil y Varela, op. cit., p. 154.

23 Véase Gil y Varela, op. cit., pp. 177-203. 
que son quienes les cuentan a los europeos que los otros, sus enemigos, son caníbales. Así pues, en ningún caso hay un avistamiento directo de prácticas de antropofagia, lo que hace que el testimonio europeo sobre el canibalismo pueda ser rebatido con relativa facilidad.

Otro aspecto relevante de esta carta es que, según Juan Gil, los textos de Chanca y Coma son

muy afines pero no iguales, persiguen un mismo objetivo, la magnificación a ultranza de lo descubierto [...] subsiste, sin embargo, un motivo de inquietud y de desconcierto máximo, y es que nadie, ni siquiera el sabelotodo D. Cristóbal Colón, conoce a ciencia cierta dónde se hallan esas islas de las que ha tomado posesión para la Corona de España. ${ }^{24}$

No se sabe con certeza si Coma tuvo acceso a la carta escrita por Chanca, o se haya basado solamente en lo que el capitán Pedro Margarit le contó, ${ }^{25}$ pese a ello, la crónica no deja de ser interesante por cuanto se trata de la apropiación renacentista de un contexto —el Caribe caníbal- que debe ser sometido: "Ellos hacen guerra continuamente a los suaves y tímidos indios para conseguir carne humana: éste es su botín, su objetivo, su caza. Devoran tribus indefensas. Se abstienen de los suyos, no comen a los caníbales". ${ }^{26}$

El mismo Margarit le habría referido a Coma haber estado en la escena del crimen, o sea, haber descubierto huellas de actos de canibalismo: "atestigua haber visto con sus propios ojos varios indios clavados en los asadores, y asados sobre fuego ardiente para la lujuriosa gula de ellos, cerca yacían arrancadas las cabezas y las extremidades". ${ }^{27}$

Simón Verde, un florentino amigo de Colón y afincado en Sevilla, pedía en su carta ser muy prudentes frente a lo que narraban los españoles; lo anterior porque aunque el capitán Antonio de Torres le contó haber visto lo mismo que refirió Margarit a Coma, Verde sospechaba que esos testimonios podían ser falsos: "Esto no sé si os lo he de referir como verdadero, por la facilidad que tienen éstos de poder contar mentiras". ${ }^{28}$ No obstante, Verde afirma haber entrevistado a uno de los caníbales capturados, quien confirmó su inclinación a la antropofagia y su arrepentimiento "y parece que de ello se avergüenza y hace señales de que está mal". ${ }^{29}$

Los anteriores testimoniales, como puede deducirse, se añadirían a otros que más tarde darían argumentos de peso a Juan Ginés de Sepúlveda para justificar la guerra contra los indios, toda vez que ésta se emprendía para

Gil y Varela, op. cit., p. 178.

Es lo que afirma Morales Padrón en Primeras cartas sobre América, p. 13.

Ibídem, p. 184.

Ibidem, p. 186.

Gil y Varela, op. cit., p. 210.

Ídem. 
defender a las víctimas de actos barbáricos no sólo en el Caribe, sino también y sobre todo en Tierra Firme. Los médicos y militares que consignaron en sus cartas el canibalismo, sin duda inauguraron un discurso que configuró el actuar en las Indias y que dividió a sus pobladores originarios en dos grupos: los asimilables y los descartables.

\section{Canibalismo y aOjamiento}

De la "Carta del doctor Diego Álvarez Chanca al Cabildo de Sevilla", llama la atención el juramento que su autor coloca al final de la misma: "Dios es testigo de que yo no he traspasado una jota en los términos de la verdad". Extrañas palabras en un texto cuyo autor, pocos años después, se dedicaría a escribir un tratado sobre el popular "mal de ojo" o aojamiento, un padecimiento asociado a la brujería, ${ }^{30}$ y cuyos síntomas eran decaimiento, angustia, anorexia, sofocos y otras señales más. La presencia de alguna de ellas podía dar cuenta del aojamiento, padecimiento que también era conocido como "fascinación".

Desde la Edad Media venía discutiéndose respecto a si la visión es una acción o una pasión. De la respuesta a esa cuestión derivaría el tratamiento del aojamiento, pues si mirar implica un sujeto visionario queda descartada la posibilidad de que el objeto mismo envíe una imagen de sí a quien lo ve. En el primer caso, el remedio debía centrarse en el sujeto. En el segundo caso, la visión sería una más bien una pasión. ${ }^{31}$ Dicha pasión podía provenir de ojos femeninos, peligrosos para los hombres civilizados, incluso si los cancioneros de la época les dedicaban múltiples piezas.

Sanz Hermida señala que el "mal de ojo" proviene de la envidia (del latín invídeo: mirada maligna) que sienten las mujeres menopáusicas y cuya condición les impide expulsar lo siniestro a través de la humedad. Los niños son sus principales víctimas por lo que ni ellos, ni lo ciegos pueden ser aojadores.

Como ya se adivina, resulta relativamente sencillo elaborar una ficción en la que Chanca identificaría aojadoras y "canibalesas". ${ }^{32}$ Esas mujeres que devoran crías que no parieron, pero que desearían fuesen suyas, no pueden, desde luego, ser cultivadas. Es decir, es imposible volverlas parte de la cultura. Antes bien, deben ser arrancadas del suelo que pisan. Canibalesas que quedarán asimiladas en la imaginería popular al modo de las brujas que comen niños o que, como mínimo, caen ante su ojo hechicero. ${ }^{33}$

Véase a Sanz Hermida, "La literatura de fascinación española en el siglo XvI", p. 958.

Ibídem, p. 964.

Así les llama Jáuregui, Canibalia. Canibalismo, calibanismo, antropofagia cultural y consumo en América Latina, p. 78.

33 Vale la pena recordar que los niños, en más de una ocasión, han estado en la mesa de los famélicos. Así mismo, en el Levítico se advierte a los judíos de terribles maldiciones divinas, como la de verse obligados a comerse a sus pequeños como castigo a su infidelidad. En el 
En todo caso, parece que a Chanca se le metieron los caníbales por los ojos y, en especial, lo que significaba su presencia. No es que los envidiara, pues la envidia es un sentimiento o práctica no discursiva; pero es obvio que al ubicarse él en un panóptico privilegiado y con el poder de enunciar a través de su misiva a un poderoso señor, los caníbales corrían gran peligro de desaparecer. Y, de hecho, lo hicieron: el caníbal fue puesto a disposición de la Ley, y se autorizó por Real Cédula del 15 de noviembre de 1505 dirigida al Gobernador de La Española, que fuera esclavizado. Chanca, en cambio, se dedicó a hacer negocios trasatlánticos igual que Verde, a quien no cohibieron ni las exageraciones de españoles ni las confesiones de los acusados de canibalismo.

Hay que recordar que Chanca viajaba en calidad de médico, pero también como informante. La conquista de tierras y rutas, que ya se planeaba desde antes del primer viaje de Colón, implicaba una apuesta por la guerra. Y toda guerra tiene por efecto el cautiverio. De ahí la importancia de la observación, ya que ningún vencedor pasa por alto la necesidad de vigilar a su cautivo.

En cierto sentido, puede decirse que tras haberle echado el ojo a América, el colonizador se convirtió en lo mismo que juró erradicar. Ésta no sería la primera vez que alguien acusa a Occidente de lo que se culpa a América. Por ejemplo, hallamos en el título de un libro de Jack D. Forbes, antropólogo y nativo americano, una denuncia directa y llana: Columbus and Other Cannibals. The Wétiko Disease of Exploitation, Imperialism, and Terrorism (2008). En ese texto, como en otros de semejante calibre, se habla de una variante del aojamiento que, siguiendo a Chanca, puede desecar al sujeto al punto de matarlo. En ambos casos (wétiko y aojamiento) se trata de padecimientos malignos y altamente contagiosos.

El windigo o wétiko se asocia tanto a la visión como a la antropofagia, según dicen los indios Cree de las montañas Rocallosas. Con esta palabra se designa a una persona enferma que aterroriza a otras y, curiosamente, también se utiliza el término para referirse a un tipo singular de anomalía psiquiátrica (la "psicosis por windigo"). ${ }^{34}$ Según la creencia, ciertas personas son poseídas por un espíritu del aire o entidad vampírica, tras lo cual se ven condenados a consumir carne humana lo que los convierte en una especie de muerto viviente, al estilo de zombis y otros seres degradados. De igual forma, wétiko también refiere al legendario Sasquatch (Pie Grande) pariente del asiático Yeti o "abominable hombre de las nieves" y que significa "hombre salvaje".

Occidente decimonónico, los cuentos con ogros y brujas cuyo platillo favorito son los niños, se acompañaron de ilustraciones de Gustave Doré (1832-1883) que impactaron tanto como las imágenes de varios textos del siglo XVI.

$34 \quad$ Véase a Pérez Sales, Psicología y psiquiatría transcultural. 


\section{REFLEXIÓN FINAL}

Podemos concluir que el caníbal ha mutado "genéticamente" sin que se hayan perdido los eslabones de la cadena. De hecho, sigue transformándose, como mito que es: "El mito del salvaje, - afirma Bartra - tal como lo retoman Calderón y Hobbes, es la metáfora perfecta para hablar de los aspectos escandalosos, infames, crueles, adúlteros, sanguinarios y caníbales de ese nuevo dios que el humanismo europeo ha comenzado a entronizar". ${ }^{35}$

Por eso no es descabellado afirmar que cuando se inventó al caníbal — desde un imaginario configurado de antemano- comenzó a trazarse la Modernidad y, con él, la crítica a ella. Lo que resta por decir es que la voracidad moderna es mucho más cruel que la de los caníbales del XVI y ha llevado a ficciones sobre mundos posapocalípticos. Es eso lo que quiere hacernos ver Carlos Jáuregui cuando escribe que:

El canibalismo ha sido un tropo fundamental en la definición de la identidad cultural latinoamericana, desde las primeras visiones europeas del Nuevo Mundo como monstruoso y salvaje, hasta las narrativas y producción cultural de los siglos Xx y xxI en las que el caníbal se ha redefinido de diversas maneras en relación con la construcción de identidades (pos)coloniales y posmodernas. ${ }^{36}$

Si el mal salvaje sobrevivió ello se debe a que es un personaje más sórdido y con mayor eficacia simbólica que su inocente contraparte. También porque es una alegoría de la ferocidad del Estado que consiguió domarlo, así como de los enemigos del mismo. ${ }^{37}$ No en balde ha gozado de gran fama aquel personaje isabelino del que más gustan los filósofos latinoamericanos: Calibán, que es víctima a la vez que victimario, pues es maldito pero también maldice. Él es, sin duda, la imagen que permite mostrar cosas más horrendas que su cuerpo deformado: los hechizos de la Modernidad que hicieron desaparecer, en nombre de la prosperidad, la alteridad americana - y hoy, la naturaleza - en medio de feroces tempestades.

\section{Bibliografía}

Arrom, José Juan, Fray Ramón Pané: Relación acerca de las antigüedades de los indios, México, Siglo XXI, 1984.

Avramescu, Cătălin, An Intellectual History of Cannibalism, New York, Princeton, University Press, 2009.

Después de Kant desaparece el Caníbal que se ve eclipsado por el Estado, nuevo agente de la crueldad absoluta. Véase Avramescu, An Intellectual History of Cannibalism, p. 262. 
Bartra, Roger, El mito del Salvaje, México, FCE, 2011.

Beuchot, Mauricio, La querella de la conquista. Una polémica del siglo XVI, México, Siglo XXI, 1992.

Cattan, Marguerite, "Fray Ramón Pané. El primer extirpador de idolatrías", Alpha, núm. 39, diciembre 2014, pp. 37-56.

Colón, Cristóbal, Diario de los cuatro viajes del Almirante y su testamento, México, Espasa-Calpe, 1986.

Colón, Cristóbal, Libro de las Profecías, Madrid, Alianza, 1992.

Gil, Juan y Varela, Consuelo (eds.), Cartas de particulares a Colón y Relaciones coetáneas, Madrid, Alianza Universidad, 1984.

Jacobo, Sanz Hermida, "La literatura de fascinación española en el siglo Xvı", Centro Virtual Cervantes,

Jáuregui, Carlos, Canibalia. Canibalismo, calibanismo, antropofagia cultural y consumo en América Latina, Córdoba, Casa de las Américas, 2005.

Las Casas, Bartolomé de, De regia potestate o derecho de autodeterminación, Madrid, CSIC, 1984.

Lienhardt, Martin, Testimonios, cartas y manifiestos indígenas (desde la Conquista hasta comienzos del siglo XX), Caracas, Ayacucho, 1992.

Morales Padrón, Francisco, Primeras cartas sobre América (1493-1503), Universidad de Sevilla, 1990.

O’Gorman, Edmundo, La idea del descubrimiento de América. Historia de esa interpretación y crítica de sus fundamentos, México, UNAM, 1951.

— La invención de América. El universalismo de la cultura de Occidente, México, FCE, 1958.

Oviedo, José Miguel, Historia de la literatura hispanoamericana. I. De los orígenes a la Emancipación, Madrid, Alianza, 2003.

Pérez Sales, Pau, Psicología y psiquiatría transcultural: bases prácticas para la acción, Bilbao, Desclée de Brouwer, 2004.

Reding Blase, Sofía, El buen salvaje y el caníbal, México, CIALC/UnAm, 2009.

Sagarra Gamazo, Adelaida, "Diego Álvarez Chanca, primer espía en América”, Revista de estudios colombinos, núm. 5, 2009, pp. 19-40.

Salas, Alberto M., Tres cronistas de Indias. Pedro Mártir de Anglería. Gonzalo Fernández de Oviedo. Fray Bartolomé de Las Casas, México, FCE, 1986.

$</$ http://cvc.cervantes.es/literatura/aiso/pdf/02/aiso_2_2_053.pdf/>, consultado el 26 de febrero de 2018.

Svet, Yákov, Cristóbal Colón, Moscú, Progreso, 1987.

Varela, Consuelo, Colón y los florentinos, Madrid, Alianza, 1988. 